\title{
Electrical and Optical Properties of ZnO Irradiated with Hydrogen Plasma
}

\author{
Koji Abe* and Hiroki Hata \\ Department of Engineering Physics, Electronics, and Mechanics, Graduate school of Nagoya Institute of Technology, Gokiso, \\ Showa, Nagoya 466-8555, Japan \\ * Corresponding author: e-mail: abe@nitech.ac.jp
}

\begin{abstract}
The influence of intrinsic defects and hydrogen-defect complexes on the properties of n-type $\mathrm{ZnO}$ crystals has been studied in terms of annealing and hydrogen plasma irradiation. Electrical and optical properties have been found to be dependent on annealing conditions and hydrogen plasma irradiation. When an as-polished sample was annealed in Ar atmosphere containing $\mathrm{Zn}$ vapor at $800^{\circ} \mathrm{C}$ for $2 \mathrm{~h}$, the color of the sample changed into orange because of the formation of oxygen vacancies $\left(\mathrm{V}_{\mathrm{O}}\right)$. In spite of the $\mathrm{V}_{\mathrm{O}}$ formation, Hall mobility of the sample increased from 162 to $210 \mathrm{~cm}^{2} \mathrm{~V}^{-1} \mathrm{~s}^{-1}$. Carrier concentration also increased by about four orders of magnitude. The simultaneous increases in carrier concentration and Hall mobility indicate that zinc vacancy $\left(\mathrm{V}_{\mathrm{Zn}}\right)$ concentration, which acts as a compensation acceptor, are decreased by supplying $\mathrm{Zn}$ vapor during the annealing. Hydrogen plasma irradiation did not affect electrical properties of the sample annealed in $\mathrm{Ar}$ atmosphere containing $\mathrm{Zn}$ vapor, but improved those of the sample annealed in pure Ar atmosphere. The carrier concentration and Hall mobility increased by hydrogen plasma irradiation decreased with increasing post-annealing temperature. The post-annealing temperature dependence suggests that $\mathrm{V}_{\mathrm{Zn}}$ passivated by hydrogen starts to dissociate at temperatures around $400^{\circ} \mathrm{C}$.
\end{abstract}

Key words: $\mathrm{ZnO}$, hydrogen, vacancy, Raman spectroscopy, carrier concentration

\section{INTRODUCTION}

Zinc oxide $(\mathrm{ZnO})$ is a non-toxic II-VI semiconductor material with a wide bandgap of $3.37 \mathrm{eV}$ and a large exciton binding energy of 60 $\mathrm{meV}$ at room temperature. Because of its outstanding properties and many types of distinctive nanostructures, $\mathrm{ZnO}$ is considered as a promising material for various applications including light emitting diodes, ultraviolet photodetectors, transparent conductive layers, and gas sensors [1-4]. A wide range of techniques such as hydrothermal method, chemical vapor deposition (CVD), reactive plasma deposition (RPD), and aqueous solution based methods are used to synthesize $\mathrm{ZnO}$ [5-9]. For example, large $\mathrm{ZnO}$ single crystals are grown by hydrothermal method. Group III elements (B, Al, and $\mathrm{Ga}$ ) are commonly used as shallow donors to form highly conductive $\mathrm{ZnO}$ films [3,7]. So far, Al- and Ga-doped $\mathrm{ZnO}$ films with a resistivity as low as $10^{-4} \Omega \mathrm{cm}$ have been reported $[10,11]$. However, it is difficult to obtain reliable p-type $\mathrm{ZnO}$. $\mathrm{ZnO}$ usually exhibits n-type conductivity despite acceptor doping. Intrinsic defects including oxygen vacancies $\left(\mathrm{V}_{\mathrm{O}}\right)$, zinc interstitials $\left(\mathrm{Zn}_{\mathrm{i}}\right)$, and zinc vacancies $\left(\mathrm{V}_{\mathrm{Zn}}\right)$, which can be formed during crystal growth under non-stoichiometric conditions, are known to act as donors or acceptors [12]. Besides the group III impurities and intrinsic defects, hydrogen plays important roles in electrical conductivity of $\mathrm{ZnO}$. It has been reported that hydrogen acts as shallow donors and makes hydrogen-defect complexes like $\mathrm{VoH}$ and $\mathrm{VznH}$ [12-14]. Hydrogen can be easily incorporated into $\mathrm{ZnO}$ crystals because hydrogen exists in a typical crystal growth environment. In order to control the electrical conductivity, therefore, hydrogen and hydrogen-defect complexes must be taken into account. However, the knowledge about their influence on electrical properties of $\mathrm{ZnO}$ (carrier concentration, Hall mobility, and resistivity) is limited.

Defect concentration of a crystal generally depends on growth conditions, but intrinsic defects in $\mathrm{ZnO}$ are formed by electron beam irradiation and annealing. However, electron beam irradiation causes damage to both zinc and oxygen sites simultaneously. On the other hand, annealing forms an individual defect by choosing an appropriate atmosphere. The controlled formation of intrinsic defects helps to observe the influence of intrinsic defects on electrical and optical properties of $\mathrm{ZnO}$. There have been a lot of studies on the properties of $\mathrm{ZnO}$ annealed in various conditions. Børseth et al. have reported that annealing at temperatures above $800{ }^{\circ} \mathrm{C}$ in $\mathrm{Zn}$-rich and O-rich atmospheres forms $V_{O}$ and $V_{Z n}$, respectively [15].

In this study, we have investigated the electrical and optical properties of n-type $\mathrm{ZnO}$ after annealing and hydrogen plasma irradiation. We discuss the influence of intrinsic defects and hydrogen-defect complexes.

\section{EXPERIMENTAL}

The samples used in this study were cut from a commercial $\mathrm{ZnO}$ crystal grown by hydrothermal method, and mechanically polished with alumina 


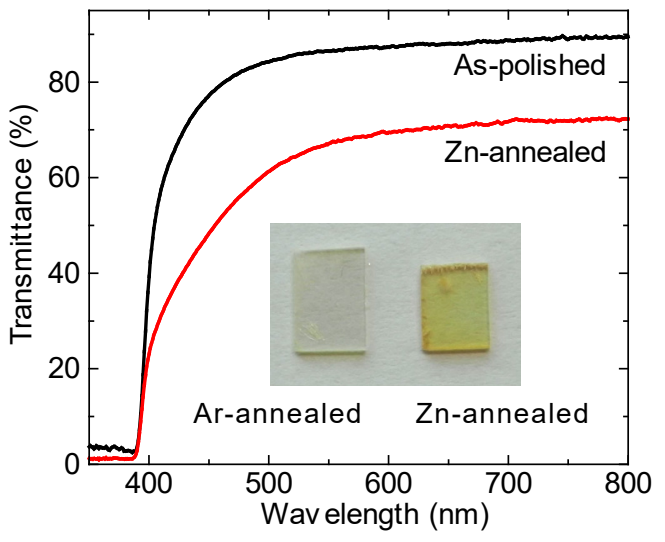

Fig. 1. Optical transmittance spectra of the as-polished and $\mathrm{Zn}$-annealed samples. The photograph shows the samples after the Ar-annealing at $800^{\circ} \mathrm{C}$ for $2 \mathrm{~h}$ (left) and $\mathrm{Zn}$-annealing at $800^{\circ} \mathrm{C}$ for $2 \mathrm{~h}$ (right).

powder. The samples were cleaned with acetone in an ultrasonic bath, and rinsed in deionized water (as-polished samples). Then, the as-polished samples were annealed in pure Ar atmosphere (Ar-annealing) or Ar atmosphere containing $\mathrm{Zn}$ vapor (Zn-annealing). The Ar-annealing was performed at $750^{\circ} \mathrm{C}$ for $30 \mathrm{~min}$ or at $800^{\circ} \mathrm{C}$ for $2 \mathrm{~h}$. The $\mathrm{Zn}$-annealing was performed at $800^{\circ} \mathrm{C}$ for $2 \mathrm{~h}$. In the $\mathrm{Zn}$-annealing process, $\mathrm{ZnO}$ powder $(99.999 \%)$ and carbon plates were placed on the bottom of an alumina crucible in a quartz tube furnace, and the as-polished sample was stuck on the crucible lid by carbon paste. After evacuated below $5 \times 10^{-3} \mathrm{~Pa}$, the quartz tube was filled with pure Ar. During the heating of the crucible, $\mathrm{Zn}$ vapor along with $\mathrm{CO}$ and $\mathrm{CO}_{2}$ was supplied to the as-polished sample through the reduction of $\mathrm{ZnO}$ powder by carbon plates. The temperatures of the bottom and lid of the crucible were $1150 \pm 20^{\circ} \mathrm{C}$ and $800 \pm 10^{\circ} \mathrm{C}$, respectively. Since the surface roughness was increased by the $\mathrm{Zn}$-annealing, the sample for optical transmittance measurements was mechanically polished with alumina powder. A conventional RF magnetron sputtering system was used for hydrogen plasma irradiation. The sample annealed in $\mathrm{Ar}$ at $750^{\circ} \mathrm{C}$ for 30 min was placed on a silicon wafer on the target electrode of the sputtering system and irradiated with hydrogen plasma $(13.56 \mathrm{MHz}, 100 \mathrm{~W})$ at a pressure of $4 \mathrm{~Pa}$ for $30 \mathrm{~min}$. The target electrode was water-cooled, but the sample temperature during the plasma irradiation was not controlled. After the hydrogen plasma irradiation, the sample was isochronally annealed in pure Ar at temperatures between 125 and $530^{\circ} \mathrm{C}$ for $30 \mathrm{~min}$ (post-annealing).

Optical transmittance was measured between 350 and $800 \mathrm{~nm}$. Raman spectra at room temperature were obtained by using a Raman spectrometer with a $532 \mathrm{~nm}$ excitation laser (NRS-3300 JASCO). Resistivity and Hall effect measurements were performed at room temperature by using the van

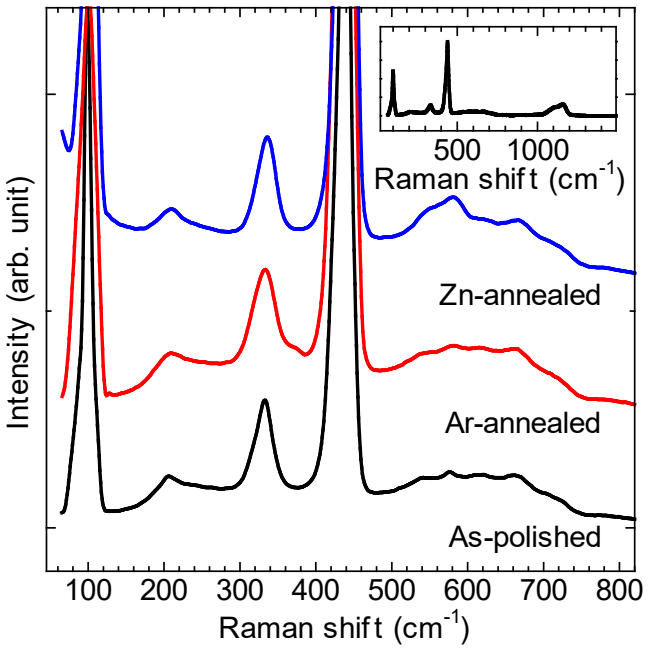

Fig. 2. Raman spectra of the as-polished, Ar-annealed, and $\mathrm{Zn}$-annealed samples. The inset shows the wide-range Raman spectrum of the as-polished sample.

der Pauw configuration. Contacts were formed by soldering indium onto the samples.

\section{RESULTS AND DISCUSSION}

As-polished samples were annealed in pure $\mathrm{Ar}$ atmosphere or $\mathrm{Ar}$ atmosphere containing $\mathrm{Zn}$ vapor at $800^{\circ} \mathrm{C}$ for $2 \mathrm{~h}$. Optical transmittance spectra of the as-polished and $\mathrm{Zn}$-annealed samples are shown in Fig. 1. The inset shows the typical photograph of the Ar-annealed and Zn-annealed samples. Although the color of the Ar-annealed sample was almost the same as that of the as-polished sample, the $\mathrm{Zn}$-annealed sample exhibited coloration. The color of the sample changed into orange as previously reported $[13,16]$. The $\mathrm{Zn}$-annealed sample showed a lower transmittance than the as-polished sample. Because of the orange coloration caused by the $\mathrm{Zn}$-annealing, optical transmittance between 400 and $500 \mathrm{~nm}$ obviously decreased. Selim et al. have reported that $V_{0}$ are responsible for the optical absorption between 400 and $500 \mathrm{~nm}$ [17]. The optical transmittance indicates that $\mathrm{V}_{O}$ are formed by the $\mathrm{Zn}$-annealing.

Raman measurements were performed to collect more information about the formation of $\mathrm{V}_{\mathrm{O}}$. Because wurtzite $\mathrm{ZnO}$ belongs to the $C_{6 v}$ symmetry group, there are six Raman-active phonon modes, $A_{1}$ (TO), $A_{1}(\mathrm{LO}), E_{2}$ (low), $E_{2}$ (high), $E_{1}(\mathrm{TO})$, and $E_{1}(\mathrm{LO})[18,19]$. The $A_{1}(\mathrm{TO}), E_{1}(\mathrm{LO})$, and $E_{1}(\mathrm{TO})$ are not seen in our measurements because of the backscattering geometry [20,21]. Figure 2 shows Raman spectra obtained from the as-polished, Ar-annealed $\left(750^{\circ} \mathrm{C}\right.$ for $\left.30 \mathrm{~min}\right)$, and $\mathrm{Zn}$-annealed samples. The inset shows the wide-range Raman spectrum of the as-polished sample. There are four Raman peaks at $98,332,439$, and $1156 \mathrm{~cm}^{-1}$. The Raman peaks at 98 and $439 \mathrm{~cm}^{-1}$ are assigned to the $E_{2}$ (low) and $E_{2}$ (high) modes, respectively $[18,19]$. The Raman peaks at 332 and $1156 \mathrm{~cm}^{-1}$ 


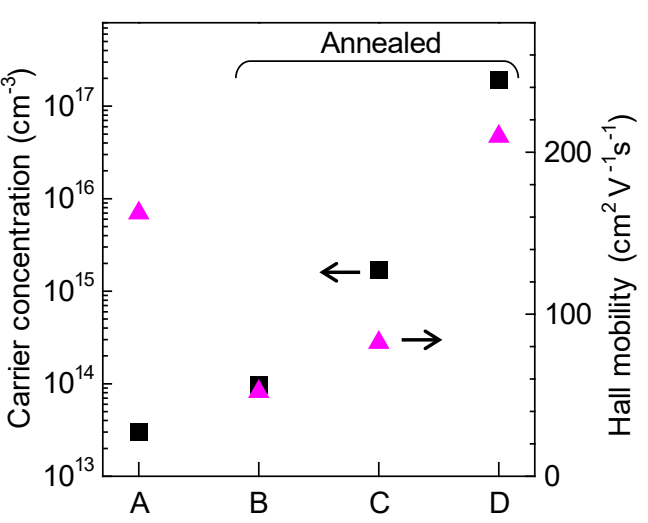

Fig. 3. Carrier concentration and Hall mobility of the as-polished sample and the samples annealed in different conditions. A: as-polished. B: Ar-annealed at $750^{\circ} \mathrm{C}$ for $30 \mathrm{~min}$. C: Ar-annealed at $800^{\circ} \mathrm{C}$ for 2 h. D: Zn-annealed at $800^{\circ} \mathrm{C}$ for $2 \mathrm{~h}$.

are known to be the second order Raman scattering $[18,20]$. The Raman spectra in Fig. 2 are normalized by the intensity of the $E_{2}$ (high) peak. In the spectrum of the Zn-annealed sample, an additional Raman peak has appeared at $581 \mathrm{~cm}^{-1}$. Chen et al. reported that this broad peak in the $\mathrm{O}^{+}$-implanted $\mathrm{ZnO}$ single crystal was much smaller than that in the $\mathrm{B}^{+}$-implanted one [21]. This broad Raman peak at around $580 \mathrm{~cm}^{-1}$ has been attributed to oxygen deficiency in $\mathrm{ZnO}$ [21-23]. The increase of the broad Raman peak indicates that $V_{O}$ was formed by the $\mathrm{Zn}$-annealing. This result is consistent with the optical transmittance spectra shown in Fig. 1.

The carrier concentration and Hall mobility of the as-polished sample and those of the samples annealed in different conditions are shown in Fig. 3 . The thickness of the samples A, B, C, and D were $1200,540,550,750$, and $550 \mu \mathrm{m}$, respectively. The carrier concentration and Hall mobility of the as-polished sample were $3.0 \times 10^{13} \mathrm{~cm}^{-3}$ and 162 $\mathrm{cm}^{2} \mathrm{~V}^{-1} \mathrm{~s}^{-1}$, respectively. When as-polished samples were annealed in pure $\mathrm{Ar}$ atmosphere, carrier concentration increased and Hall mobility considerably decreased. The carrier concentration and Hall mobility of the sample after the Ar-annealing at $750^{\circ} \mathrm{C}$ for $30 \mathrm{~min}$ were $9.7 \times 10^{13}$ $\mathrm{cm}^{-3}$ and $52 \mathrm{~cm}^{2} \mathrm{~V}^{-1} \mathrm{~s}^{-1}$, respectively. After the Ar-annealing at $800^{\circ} \mathrm{C}$ for $2 \mathrm{~h}$, the carrier concentration and Hall mobility of the sample were $1.7 \times 10^{15} \mathrm{~cm}^{-3}$ and $83 \mathrm{~cm}^{2} \mathrm{~V}^{-1} \mathrm{~s}^{-1}$, respectively. The $\mathrm{Zn}$-annealing at $800^{\circ} \mathrm{C}$ for $2 \mathrm{~h}$ resulted in significant changes of the electrical properties. In spite of the formation of $\mathrm{V}_{O}$ by the $\mathrm{Zn}$-annealing, carrier concentration increased to $1.9 \times 10^{17} \mathrm{~cm}^{-3}$, and Hall mobility increased to $210 \mathrm{~cm}^{2} \mathrm{~V}^{-1} \mathrm{~s}^{-1}$. These values are much higher than those of the as-polished and Ar-annealed samples. It is known that $\mathrm{V}_{\mathrm{O}}$ forms a deep donor level in $\mathrm{ZnO}$ and cannot contribute to the increase of carrier concentration and Hall mobility [12]. The

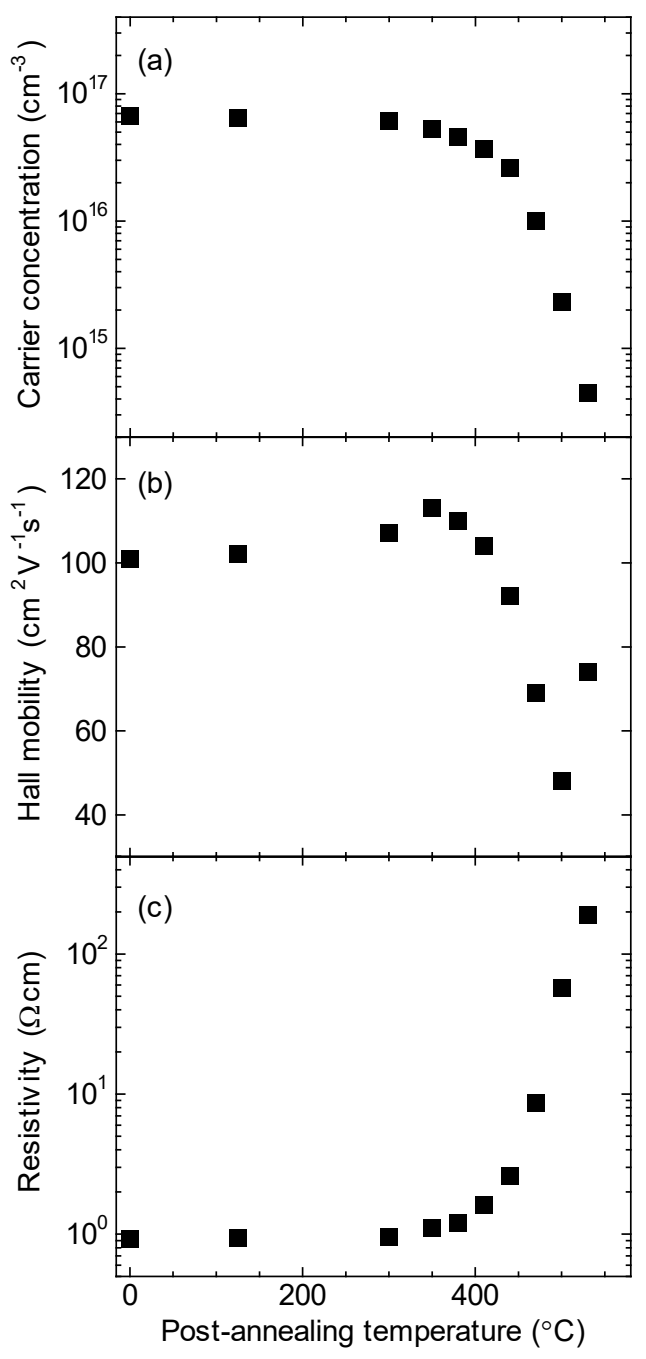

Fig. 4. Electrical properties of the sample irradiated with hydrogen plasma as a function of post-annealing temperature: (a) carrier concentration, (b) Hall mobility, and (c) resistivity.

simultaneous increase of carrier concentration and Hall mobility indicates that the $\mathrm{Zn}$-annealing reduces the concentration of compensation acceptors. It seems that $\mathrm{V}_{Z n}$ concentration is decreased by supplying $\mathrm{Zn}$ vapor during the annealing.

In order to observe the thermal stability of the electrical properties after hydrogen plasma irradiation, the sample irradiated with hydrogen plasma was post-annealed in Ar. The Ar-annealed sample $\left(750^{\circ} \mathrm{C}, 30 \mathrm{~min}\right)$ were irradiated with hydrogen plasma. Figures 4(a)-4(c) show electrical properties of the sample as a function of post-annealing temperature. The thickness of the sample was $860 \mu \mathrm{m}$. The carrier concentration and Hall mobility of the sample before post-annealing were $6.7 \times 10^{16} \mathrm{~cm}^{-3}$ and $101 \mathrm{~cm}^{2} \mathrm{~V}^{-1} \mathrm{~s}^{-1}$, respectively. These values were higher than those of the sample after the Ar-annealing at $750^{\circ} \mathrm{C}$ for 
30 min (Fig. 3). It was found that carrier concentration and Hall mobility are increased by hydrogen plasma irradiation. Electrical properties of the sample were almost unchanged by the post-annealing at temperatures below $300^{\circ} \mathrm{C}$. In the range from 300 to $380^{\circ} \mathrm{C}$, the carrier concentration decreased and the Hall mobility slightly increased with increasing post-annealing temperature. A further increase of post-annealing temperature significantly changed the electrical properties. Along with the simultaneous decreases in carrier concentration and Hall mobility, resistivity increased about two orders of magnitude. The carrier concentration, Hall mobility, and resistivity of the sample after the post-annealing at $530^{\circ} \mathrm{C}$ were $4.5 \times 10^{14} \mathrm{~cm}^{-3}, 74 \mathrm{~cm}^{2} \mathrm{~V}^{-1} \mathrm{~s}^{-1}$, and $1.9 \times 10^{2}$ $\Omega \mathrm{cm}$, respectively. These values were almost the same as those obtained from the sample after the Ar-annealing at $750^{\circ} \mathrm{C}$ for $30 \mathrm{~min}$ (Fig. 3). It was indicated that compensation acceptors are passivated by hydrogen and the passivated acceptors are reactivated at the temperatures around $400^{\circ} \mathrm{C}$. The electrical properties of the Ar-annealed sample were improved by hydrogen plasma irradiation, while the electrical properties of the $\mathrm{Zn}$-annealed sample were not affected by the hydrogen plasma irradiation. When the $\mathrm{Zn}$-annealed sample was irradiated with hydrogen plasma, the carrier concentration and Hall mobility were $2.5 \times 10^{17} \mathrm{~cm}^{-3}$ and $188 \mathrm{~cm}^{2} \mathrm{~V}^{-1} \mathrm{~s}^{-1}$, respectively. As discussed in Fig. 3, the $\mathrm{Zn}$-annealing at $800^{\circ} \mathrm{C}$ for 2 $\mathrm{h}$ decreases the concentration of $\mathrm{V}_{\mathrm{Zn}}$. It is likely that formation and dissociation of hydrogen- $\mathrm{V}_{\mathrm{Zn}}$ complexes affect carrier concentration and Hall mobility of n-type $\mathrm{ZnO}$.

\section{CONCLUSIONS}

In conclusion, we have studied the influence of intrinsic defects and hydrogen-defect complexes on the electrical and optical properties of n-type $\mathrm{ZnO}$ crystals. When an as-polished sample was annealed in $\mathrm{Ar}$ containing $\mathrm{Zn}$ vapor at $800^{\circ} \mathrm{C}$ for $2 \mathrm{~h}$, the color of the sample changed into orange. Optical transmittance and Raman measurements showed that $V_{O S}$ were formed by the $\mathrm{Zn}$-annealing. Although the concentration of $V_{O}$ increased, electrical properties were improved by the $\mathrm{Zn}$-annealing. The carrier concentration and Hall mobility of the sample were much higher than those obtained from the as-polished sample. The simultaneous increase of carrier concentration and Hall mobility indicates that the $\mathrm{Zn}$-annealing reduces the concentration of $V_{Z n}$ which acts as compensation acceptors. Hydrogen plasma irradiation did not affect the electrical properties of the $\mathrm{Zn}$-annealed sample, but improved those of the Ar-annealed sample. The carrier concentration and Hall mobility of the Ar-annealed sample were simultaneously increased by hydrogen plasma irradiation, indicating that hydrogen passivates the compensation acceptors. The electrical properties improved by hydrogen plasma irradiation were stable at temperatures below $300^{\circ} \mathrm{C}$. It was found that the compensation acceptors passivated by hydrogen starts dissociating at temperatures around $400^{\circ} \mathrm{C}$.

The conditions of annealing and hydrogen plasma irradiation in this study can be applied to improve electrical properties of n-type $\mathrm{ZnO}$ crystals.

\section{REFERENCES}

[1] D. C. Look, B. Claflin, Ya. I. Alivov, and S. J. Park, phys. stat. sol. (a), 201, 2203-2212 (2004).

[2] H. Endo, M. Sugibuchi, K. Takahashi, S. Goto, S. Sugimura, K. Hane, and Y. Kashiwaba, Appl. Phys. Lett., 90, 121906 (2007).

[3] T. Minami, T. Miyata, and J. Nomoto, Mater. Sci. and Eng., 34012001 (2012).

[4] M.-W. Ahn, K.-S. Park, J.-H. Heo, J.-G. Park, D.-W. Kim, K. J. Choi, J.-H. Lee, and S.-H. Hong, Appl. Phys. Lett., 93, 263103 (2008).

[5] K. Maeda, M. Sato, I. Niikura, and T. Fukuda, Semicond. Sci. Technol., 20, S49-S54 (2005).

[6] J.G. Lu, T. Kawaharamura, H. Nishinaka, Y. Kamada, T. Ohshima, and S. Fujita, J. Cryst. Growth, 299, 1-10 (2007).

[7] K. Iwata, T. Sakemi, A. Yamada, P. Fons, K. Awai, T. Yamamoto, S. Shirakata, K. Matsubara, H. Tampo, K. Sakurai, S. Ishizuka, and S. Niki, Thin Solid Films, 480-481, 199-203 (2005).

[8] K. Abe and M Miura, Jpn. J. Appl. Phys., 51, 071101 (2012).

[9] L. Chow, O. Lupan, H. Heinrich, and G. Chai, Appl. Phys. Lett., 94, 163105 (2009).

[10] N. Yamamoto, H. Makino, S. Osone, A. Ujihara, T. Ito, H. Hokari, T. Maruyama, and T. Yamamoto, Thin Solid Films, 520, 4131-4138 (2012).

[11] J. Nomoto, T. Miyata, and T. Minami, J. Vac. Sci. Technol. A, 29, 041504, 2011.

[12] E. V. Lavrov, F. Herklotz, and J. Weber, Phys. Rev. B, 79, 165210 (2009).

[13] J. Cizek, J. Valenta, P. Hruska, O. Melikhova, I. Prochazka, M. Novotny, and J. Bulir, Appl. Phys. Lett., 106, 251902 (2015).

[14] A. Janotti and C. G. Van de Walle, Rep. Prog. Phys., 72, 126501 (2009).

[15] T. Moe Børseth, B. G. Svensson, A. Yu. Kuznetsov, P. Klason, Q. X. Zhao, and M. Willander, Appl. Phys. Lett., 89, 262112 (2006).

[16] L. E. Halliburton, N. C. Giles, N. Y. Garces, Ming Luo, Chunchuan Xu, Lihai Bai, and L. A. Boatner, Appl. Phys. Lett., 87, 172108 (2005).

[17] F.A. Selim, M.H. Weber, D. Solodovnikov, and K.G. Lynn, Phys. Rev. Lett., 99, 085502 (2007).

[18] T. C. Damen, S. P. S. Porto, and B. Tell, Phys. Rev. 142, 570-574 (1966).

[19] M. Yoshikawa, K. Inoue, T. Nakagawa, H. Ishida, N. Hasuike, and H. Harima, Appl. Phys. Lett., 92, 113115 (2008).

[20] R. Cuscó, E. Alarcón-Lladó, J. Ibáñez, L. Artús, J. Jiménez, B. Wang, and M. J. Callahan, Phys. Rev. B, 75, 165202 (2007).

[21] Z. Q. Chen, M. Maekawa, A. Kawasuso, S. Sakai, and H. Naramoto, J. Appl. Phys., 99, 093507 (2006). 
[22] X. Xue, T. Wang, X. Jiang, J. Jiang, C. Pan, and Y. Wu, CrystEngComm, 16, 1207-1216 (2014).

[23] A. Kaschner, U. Haboeck, M. Strassburg, M. Strassburg, G. Kaczmarczyk, A. Hoffmann, C. Thomsen, A. Zeuner, H. R. Alves, D. M. Hofmann, and B. K. Meyer, Appl. Phys. Lett., 80, 1909-1911 (2002).

(Received April 18, 2016; Accepted June 6, 2016; Published Online September 1, 2016) 